\title{
Arnold Hauser. Un análisis metodológico de "Impresionismo" extraído de su Historia Social de la Literatura y el Art
}

Arnold Hauser A methodological analysis of "Impressionism" drawn from its Social History of Literature and Arte

\author{
Mónica Serrano Segui \\ Historia del Arte, Universidad Complutense de Madrid, España (mserra01@ucm.es)
}

Recibido el 17 de noviembre de 2017; revisado el 10 de enero de 2018; aceptado el 18 de febrero de 2018; publicado el 21 de marzo de 2018

RESUMEN: El siguiente artículo tiene como finalidad analizar, desde un punto de vista metodológico y de la Teoría del Arte como disciplina, el capítulo que Arnold Hauser dedica al arte del impresionismo en su Historia Social de la Literatura y el Arte. Para ello, se realizará un estudio crítico del mismo teniendo en cuenta el contexto histórico en el que se produce y su relación con las distintas escuelas dedicadas a la teoría y metodología del arte, incluyendo los recientes estudios visuales.

PALABRAS CLAVE: Teoría, Metodología, Historia Social del Arte.

\begin{abstract}
:
The following article aims to analyze, from the perspective of the theory and methodology of the art as a discipline, the chapter that Arnold Hauser dedicates to the Impressionism in his Social History of Art. To do so, a critical study is going to be made, considering the historical context in which this work was born and putting the whole thing in relation to the different schools of theory and methodology of the art, including the latest visual studies.
\end{abstract}

KEYWORDS: Theory, Methodology, Social History of Art. 


\section{Introducción}

La teoría del arte es toda construcción conceptual existente acerca del arte centrada en el análisis de su significado, en la función que tiene en la sociedad, en su patronazgo y en la identificación de la finalidad del artista que lo ha generado. Por otro lado, la metodología es la aplicación de esas teorías al estudio práctico de la historia del arte como disciplina. En este sentido, resulta pertinente hacer alusión al libro sobre teoría y metodología del arte de Michael Hatt y Charlotte Klonk, donde con una metáfora se paragona la teoría a un mapa y el método al camino que se ha de encontrar (Hatt y Klonk, 2006, p. 2).

Actualmente, se sabe que toda metodología resulta útil para el estudio de la historia del arte, siempre y cuando ésta se emplee con sentido crítico y en colaboración con otras disciplinas. Pensemos en el método biográfico y su posterior historia de las generaciones, derivada de la sociología de Compte y Stuart Mill; en el atribucionismo; en el formalismo; en las teorías psicoanalíticas; en la iconografía; en la iconología o en la sociología del arte. Entre los estudios más recientes se ha de destacar una nueva disciplina o "colaboración entre disciplinas" o incluso "movimiento" (Bal, 2004, p.12) conocido como estudios visuales, donde precisamente se ha querido dotar al objeto de una visión más completa de la tradicional.

El objetivo de los estudios visuales - siguiendo el concepto de interdisciplinareidad desarrollado por Roland Barthes para la creación de un método nuevo, que actúe en consonancia con la sociedad del momento - se basa en la vinculación de disciplinas y sus respectivas metodologías para ofrecer un modelo coherente de análisis, no sólo del objeto artístico tradicional sino de todo lo que se entiende por visual (Hooper-Greenhill, 2000, p.14), sin soslayar la crítica autorreflexiva del objeto y la metodología.

La historia social del arte, encabezada por los discípulos de Max Dvorak: Frederick Antal, Arnold Hauser y Francis D. Klingender, surge a raíz del Segundo Conflicto Bélico Mundial y a partir de los estudios sociológicos de Max Weber, Georg Simmel, Karl Mannheim y de la "estética sociológica" redefinida por los pensadores marxistas ${ }^{1}$ (Marías, 1996, p.117). Por otra parte, Peter Burke, en su revisión de la obra de Francastel sobre Sociología del Arte, definía esta última como "el estudio de las relaciones entre arte y sociedad a nivel general, distinguiéndola de la historia social del arte, que es el estudio de las mismas relaciones a nivel particular” (Burke, 1971, p. 150).

${ }^{1}$ Cabe mencionar a György Lukács y al griego Nicos Hadjinicolau, a la escuela de Frankfurt con Max Horkheimer y Theodor Adorno, a Walter Benjamin con su concepto de aura y a Guy Debord por sus teorías sobre el espectáculo. 
El capítulo que Hauser dedica al Impresionismo forma parte de su Historia Social de la Literatura y el Arte, publicada por primera vez en versión inglesa en 1951 y donde el autor muestra su vinculación con las ideas marxistas. Por tanto, la obra de Hauser ha de leerse teniendo en consideración tanto la proveniencia de su método como su relación con otras metodologías, ya sean de la época o más recientes.

\section{Análisis teórico y metodológico de "impresionismo" de Arnold Hauser}

Las teorías marxistas sitúan, con salvedades, el arte dentro de la superestructura, concibiéndolo como otro medio más para la dominación de las masas. En este sentido desempeñan un papel determinante la ideología y los conceptos de falsa conciencia, denunciados por los marxistas y por los que según éstos ha sobrevivido la sociedad capitalista ${ }^{2}$ (Hauser, 1993, p. 256).

Estas ideas fueron revisadas en la segunda mitad del siglo XX, tras el progreso de la Unión Soviética y el totalitarismo de Stalin, momento en el que se empezó a manifestar un cierto rechazo. Sin embargo, partirán de ésta diversas disciplinas como la sociología del arte, que aquí nos ocupa, y otras teorías de transformación social, en cierto modo derivadas de la misma, a partir de los años 60 y 70 como el feminismo (con figuras como Laura Mulvey, Griselda Pollock, Mieke Bal o Rosalind Kraus), el postcolonialismo y los ya mencionados estudios visuales. En este sentido, cabe mencionar a Baxandall por sus teorías de la percepción como Period eye y a Svetlana Alpers por su The Art of Describing.

En relación con el valor autónomo de la imagen, Peter Burke marcó un antes y un después con sus nuevas formas de hacer historia y con su concepto de" historia desde abajo", apelando a la colaboración entre la historia del arte y la historia social y estableciendo el uso de la imagen como fuente en sí misma (Burke, 2001, p. 185). Asimismo, historiadores del arte como Michael Camille, en obras como El ídolo gótico. Ideología y creación de imágenes en el arte medieval, llevan a cabo un estudio de las imágenes sin considerarlas parte de la "ideología” sino como ideológicas en sí mismas y capaces de activar significados.

Así pues, el método de Hauser resulta útil si se concibe dentro del contexto histórico y cronológico en el que nace, pues ofrece una visión alternativa a la tradicional aunque con evidentes problemáticas y limitaciones. Entre éstas, por ejemplo, reside el hecho de atribuir todo cambio

\footnotetext{
${ }^{2}$ El mismo Marx reflexionó acerca del arte y su posible capacidad de trascender las limitaciones de la sociedad en la introducción de su Manuscrito, Grundrisse e der Kritik der Politischen Ökonomie, escrito entre 1857-61 y publicado en alemán por primera vez en 1939.
} 
experimentado en el arte a factores principalmente políticos y económicos y el recurrir al análisis formal para corroborar su teoría, en ocasiones, obviando advenimientos cruciales o casuales externos a la organización del sistema. En virtud de ello, estudiosos de otras metodologías, como Gombrich, lo han criticado por su excesiva simplicidad (Gombrich, 1953) y otros sociólogos del arte, como Pierre Francastel, han llegado a tacharle de superficial (Francastel, p. 403, 1958).

Este hecho enlaza con las críticas dirigidas a otra disciplina en su aplicación a la historia del arte: el psicoanálisis. Aunque éste también tendrá mucha repercusión en distintos momentos del siglo $\mathrm{XX}$, principalmente con el surrealismo y posteriormente con el feminismo, en ocasiones emite juicios de poco rigor científico para confirmar su teoría. Asimismo, serán otras cuestiones las que relacionen estas dos disciplinas, pues tanto el marxismo, del cual deriva gran parte el método de Hauser, como el psicoanálisis tienen en común el contexto histórico en el que se fundan y la idea de represión de los impulsos dentro de la sociedad civilizada. En este sentido, Hauser define el impresionismo como "un arte ciudadano por excelencia y no sólo porque descubre la ciudad como paisaje y devuelve la pintura desde el campo a la ciudad sino porque ve el mundo con ojos de ciudadano y reacciona con los nervios sobreexcitados del hombre técnico moderno" (Hauser, 1993, p. 196).

Ambas disciplinas hacen alusión a la dicotomía entre "principio del placer" y "principio de realidad". De hecho, el término "nervios" al que alude Hauser puede ponerse en relación directa con la neurosis. Del mismo modo, al hablar de la concepción del naturalismo - refiriéndose a la literatura - emplea el término "salvaje" (Hauser, 1993, p. 210), idea que entronca con los conceptos de barbarie y civilización de las teorías freudianas. Igualmente, hace uso de la palabra "manía", fase intrínseca del triunfo de la figura del "yo" en la que el enfermo, en estado de exaltación constante, se interesa por todo lo que le rodea sin poder detenerse en algo concreto: “el rápido desarrollo de la técnica no sólo acelera el cambio de las modas sino también las variaciones en los criterios del gusto estético; a menudo trae consigo una manía de innovación estéril y sin sentido, una lucha sin descanso por lo nuevo, por el simple gusto de la novedad" (Hauser, 1993, p. 196).

Otros elementos del texto permiten seguir poniendo en relación el pensamiento de Hauser con las teorías psicoanáliticas, especialmente en lo que concierne al sentimiento de pérdida ligado a la soledad suscitada por la gran multitud (Hauser, 1993, p. 205), que en cierto sentido reconduce a los problemas de identidad planteados por Lacan en la fase del espejo. Por otro lado, la sensación de fugacidad y pasividad ante la cual el observador no es capaz de reaccionar sino de esperar y mantenerse neutral con la contemplación, parece sugerir que hay algo que trasciende el entendimiento, como si se tratara de una realidad inasible. Esta idea pesimista del arte, que se aleja 
de los conceptos de sublimación estipulados por Freud, no libera lo reprimido a través de la observación sino que ésta produce angustia y pérdida de control de la realidad: " toda imagen impresionista es la expresión de un momento en el perpetuum mobile de la existencia, la representación de un equilibrio inestable, siempre amenazado, en el juego de las fuerzas contendientes" (Hauser, 1993, p. 197). Del mismo modo Lacan en sus teorías sobre la visión, enunciadas en su seminario número 11, manifestaba una idea pesimista del arte, derivada de la insatisfacción propiciada por la visión incompleta de la realidad. En la parte dedicada a "la anamorfosis" establecía que: "este cuadro [los Embajadores de Hans Holbein] es, sencillamente, lo que es todo cuadro, una trampa de cazar miradas. En cualquier cuadro, basta buscar la mirada en cualquiera de sus puntos, para, precisamente, verla desaparecer" (Lacan, 1964, p. 96 ).

Que Hauser reduzca el cambio estilístico surgido con el impresionismo a factores económicos y sociales le lleva a no mencionar a artistas concretos, a menos que sea para establecer los límites cronológicos del movimiento, tomando la muerte de Cézanne como fin del postimpresionismo (Hauser, 1993, p. 203) o bien para determinar la clase social a la que pertenecen: “[...] Manet, Bazille, Berthe Morisot y Cézanne son hijos de gente rica, Degas es de origen aristocrático, y Toulouse Lautrec, de la alta aristocracia" (Hauser, 1993, p.206), pues a diferencia de los líderes del método atribucionista, al autor no le interesa crear una Historia del Arte con nombres propios.

Este hecho le aproxima al método formalista, encabezado por Wölfflin y Riegl, en el cual se “formó" y del cual se distanció al descubrir que para él el verdadero desencadenante del cambio era el sistema político y económico. Otro elemento que cabe mencionar en cuanto a su tratamiento del arte o de su agrupación por estilos, es la voluntad por manifestar una continuidad entre unos y otros evitando escisiones netas, lo que concierne un enfoque más amplio y menos categórico respecto a otras disciplinas (Hauser, 1993, p.194):

"Las fronteras entre Naturalismo e Impresionismo son borrosas; es imposible establecer una distinción histórica o conceptual tajante entre ambas corrientes. La suavidad del cambio estilístico corresponde a la continuidad del desarrollo económico contemporáneo y a la estabilidad de las condiciones sociales. 1871 es un año de significado meramente transitorio en la historia de Francia".

Desde este punto de vista su obra presenta claras dicotomías con L'impressionnisme publicado por Francastel en 1937. Aunque ambos analizan el arte desde el punto de vista sociológico, lo que para Hauser es pasividad y realidad determinada por la vida metropolitana para Francastel es la aplicación del espíritu científico a la pintura (Francastel, 1983, p. 109). De igual modo, ambos 
autores difieren en el modo de aplicar su método; Hauser elude el análisis individual de los artistas mientras para Francastel, éste es precisamente el punto de partida para establecer conexiones (Francastel, 1983, p. 15).

Al igual que los formalistas y los recientes estudios visuales, Hauser alude en el texto a las teorías de la percepción, denotando un particular interés por la psicología de la forma — surgida a raíz de Über Gestaltqualitäten, tratado de Von Ehrenfels, publicado en 1890 - que también lo aproxima a las ideas de Arnheim acerca del pensamiento en imágenes al afrontar el tema del color: "El impresionismo recurre a la verdadera percepción, más allá de los colores conscientes, teóricamente válidos, lo que por lo demás no es un acto espontáneo ni mucho menos, sino que representa un proceso psicológico sumamente artificioso y extremadamente complicado" (Hauser, 1993, p. 202). Dichas leyes de la percepción, ya expuestas por Wilhelm Wundt, surgen de ideas kantianas. De hecho, la mayoría de formalistas como Wölflin - mayoría puesto que algunos abogan por el valor autónomo del arte $^{3}$, como Karl Schnnase (1843) - , afirman que el cambio estilístico se da debido a un factor externo al arte ${ }^{4}$.

Por otro lado, ambos métodos, el formalismo y el marxismo, insisten en la búsqueda de lo absoluto, de unos valores universales aplicables a cada una de las distintas épocas históricas; aunque en el caso de Hauser éstos estarían de nuevo determinados única y exclusivamente por la estructura social y política. Por consiguiente, dicha teoría de lo absoluto, que parte de las ideas hegelianas, no es aplicada por el autor desde un punto de vista estético sino que le lleva a tratar el arte "desde fuera", en sentido opuesto a los atribucionistas, semiólogos e iconólogos.

Respecto al naturalismo, término con el que se refiere al arte de Courbet, Millet y Daumier, y que define como un arte proletario en origen, el impresionismo elude la problemática social, resultando un arte por y para los artistas, una falacia de lo que no fue y nos gustaría que hubiera sido: "Somos no sólo la suma de los distintos momentos de nuestra vida, sino el resultado del aspecto que estos momentos adquieren a través de cada nuevo momento. [...]; La existencia adquiere vida actual, movimiento, color, transparencia, ideal y contenido espiritual a partir de la perspectiva de un presente que es el resultado de nuestro pasado" (Hauser, 1993, pp. 262-263).

El método de Hauser ha sido sometido a innumerables críticas, pues la creación artística no debe reducirse al mero testimonio histórico derivado de las transformaciones políticas, ideológicas y sociales, ya que éstas no pueden considerarse como único motor para su desarrollo y devenir.

\footnotetext{
${ }^{3}$ Hauser acaba reconociendo que el arte es capaz de trascender lo fútil de la sociedad capitalista.

${ }^{4}$ Alois Riegl alude a la percepción y a la voluntad artística colectiva o Kunstwollen mientras Heinrich Wölfflin no llega a profundizar en ello.
} 
Paradójicamente, desde el punto de vista metodológico, centrarse únicamente en los hechos políticos y económicos genera un aislamiento de los hechos sociales en sí, limitando la disciplina y convirtiéndola en un mero experimento, inexacto y de escaso rigor científico. Teniendo en consideración las palabras de Bauman, "la sociología es una actividad crítica, en la medida en que lleva a cabo una continua deconstrucción derridiana de la percepción de la realidad social [...]" (Bauman, 2014, p. 41), el objeto y la obra de arte han de someterse a un análisis que persiga los mismos objetivos para acceder al conocimiento de una realidad concreta. Por el contrario, tampoco tiene cabida enfrentarse a la obra de arte considerando únicamente la biografía del autor o bien la forma artística en sí misma. El método de Hauser es un compendio de sociología, psicología e historia del arte y una dialéctica constante entre la sociología tradicional y el "arte por el arte" del formalismo; una dialéctica derivadada de la superación de la existencia fragmentaria y atomizada del hombre determinado por la historia, que le llevará durante toda su vida a plantearse la función y la finalidad del arte y si el cambio en la sociedad corresponde al inevitable cambio en el arte y viceversa.

\section{Conclusiones}

Tras haber analizado el capítulo que Hauser dedica al impresionismo, prestando especial atención a la primera parte del volúmen en el que se encuentra - destinado al estudio del Mundo Moderno y Contemporáneo - principalmente la del "segundo imperio", se puede establecer que, sin duda, se trata de uno de los más sobresalientes de su Historia Social la Literatura y el Arte; el convulso siglo XIX, es seguramente, el más susceptible de ser analizado desde un punto de vista sociológico. Nunca antes la revolución social había adquirido semejante peso y es esto precisamente lo que propicia que Hauser conciba el inicio de la centuria a partir de 1830, con la "Revolución de Julio" y sus consecuencias, incluyendo entre éstas lo que Hobsbawm denomina "Primavera de los Pueblos".

Las continuas referencias al marxismo resultan por tanto apropiadas, pues es en este contexto histórico cuando se origina, a raíz del auge de la sociedad burguesa y el rápido desarrollo de las ciudades. Del mismo modo, se hace evidente la reminiscencia del psicoanálisis, otra de las corrientes tardodecimonónicas que más influirán en su método. Sin embargo, se ha de precisar que Hauser no ve el impresionismo sólo con los ojos de Marx y con el filtro de las teorías freudianas sino que va más allá, actualizándo su pensamiento, estableciendo los fines y los límites de la sociología y, en el caso de Freud particularmente, revisando sus fundamentos. En este sentido, son mayores las correspondencias con la obra de Lacan que con el padre del psicoanálisis (Hauser, ed. 1993, p. 258). 
No obstante la aplicación de su método al impresionismo da lugar a conspicuas observaciones y presenta un enfoque más afín a lo multidiscipliar, se añoran algunos elementos, quizá más propios del historiador y del historiador del arte que del sociólogo. Asimismo, es posible que en este capítulo, y en general en la primera parte dedicada al Mundo Moderno y Contemporáneo, logre enmascarar su voluntad de acotar el todo a un contexto político y económico, resultando más evidentes las carencias y la finalidad de sus disertaciones en los capítulos dedicados a periodos histórico-artísticos precedentes. Por otra parte, se evidencia en su tratamiento holístico una falta de sistematización, pues, aunque discierna entre periodos y estilos algunos de sus juicios quedan soslayados debido a la falta de documentación y a paralelismos generalizadores.

Asimismo, se puede afirmar que para Hauser, aunque en ocasiones el límite entre l'art pour l'art y el arte con una función social, sea sutil, en el impresionismo parece asumir que la obra de arte debe ser concebida como medio y no como fin. En el capítulo dedicado al "segundo imperio", donde afonda en los principios del arte naturalista, puede observarse un entusiasmo y un optimismo que queda latente en el impresionismo: "Las grandes obras de arte renuncian al ilusionismo engañoso de un mundo estético cerrado en sí mismo y van más allá de sí mismas. Están en relación directa con los grandes problemas vitales de su tiempo y buscan siempre una respuesta a estas preguntas: ¿Cómo se puede hallar un sentido a la vida humana? ¿Cómo podemos nosotros participar de este, sentido?” (Hauser, 1993, p. 29).

A su vez cuando afirma que el naturalismo había generado un incremento del patrimonio de la pintura, refiriéndose a la abolición de la jerarquía de géneros establece que (Hauser, 1993, pp. 200201):

“[...] el método impresionista, por el contrario, trae consigo una serie de reducciones, un sistema de limitaciones y simplificaciones [...];se la puede también considerar como un alejamiento de la realidad y ver la limitación de la pintura a los temas «propios» como una decadencia desde el punto de vista naturalista. La sonrisa que los griegos habían descubierto para las artes plásticas y que, como se ha observado, se ha perdido en el arte moderno, cae víctima del ver de manera «pictórica»; pero con ella desaparece al mismo tiempo de la pintura toda psicología y todo humanismo".

Estas ideas que hallan correspondencia en Sobre el principio del arte de Proudhon, hacen que Hauser vea el impresionismo engañoso, superficial y fútil, como en su opinión lo era el mundo urbano de aquel momento. Un arte conformista, claro ejemplo de adaptación y anulación del individuo determinado por el tiempo, que suscita la impresión: "El cambio de nuestra concepción del tiempo, y con él de toda nuestra experiencia de la realidad, se consuma paso a paso primero en la 
pintura impresionista, después en la filosofía de Bergson, y, finalmente, del modo más explícito y significativo, en la obra de Proust" (Hauser, 1993, p. 262).

Para Hauser el impresionismo es el sumun del esteticismo, una realidad centrada en sí misma, que sin querer resultar excesivamente molesta, causa confusión en el público. Un efecto inaudito, epígono y colofón de un proceso iniciado tiempo atrás, resultando la victoria hegemónica de la pintura sobre las demás artes (Hauser, 1993, pp. 201-202).

En 1958, Hauser publicó su Philosophie der Kunstgeschichte, en cuya introducción expresaba que aunque el arte esté socialmente condicionado, no todo en el arte es sociológicamente definible (Hauser, 1961, p. 27). Si se piensa en una de las últimas frases de "impresionismo", donde vuelven a ponerse de manifiesto las conexiones entre marxismo y psicoanálisis: "En cierto modo todos ellos [Nietzsche, Marx y Freud] descubrieron que la autodeterminación de la mente era una ficción y que nosotros somos una fuerza que trabaja en nosotros y con frecuencia contra nosotros" (Hauser, 1993, p. 257), se puede percibir esa dialéctica interna que le llevaba a cuestionarse y reconocer los propios límites de su método.

Este hecho nos permite concluir esta breve reflexión en torno a la compleja figura y obra de Hauser, en la cual se ha intentado poner de manifiesto tanto los pros como los contras de la misma, efectuando una lectura bajo el prisma de varías metodologías anteriores, contemporáneas y posteriores al autor. Todo esto nos lleva al inicio de este artículo, a las "nuevas formas de hacer historia" y en cómo la cooperación entre éstas son la clave para encontrar el "camino", al cual se referían Hatt y Klonk (2006, p. 2), que conduzca a un resultado global del conocimiento y por tanto, al éxito de la aplicación de sus distintas metodologías.

\section{Referencias Bibliográficas}

BAL, Mieke (2004), "El esencialismo visual y el objeto de los estudios visuales", Estudios Visuales, $\mathrm{n}^{\circ} 2$, pp. 11-50.

BAUMAN, Zygmunt (2014). ¿Para qué sirve realmente un sociólogo?, Paidós: Barcelona. BREA, José Luis (2006), “Estética, Historia del Arte”, Estudios Visuales, n³, pp. 8-25.

BURKE, Peter (1971), "Problems of the Sociology of Art: The Work of Pierre Francastel", European Journal of Sociology, 12 (1), pp. 141-154.

BURKE, Peter (1993). Formas de hacer Historia, Alianza: Madrid. 
BURKE, Peter (2001). Eyewitnessing. The uses of images as historical evidence, Reaktion Books: London.

CAMILLE, Michael (2000). El ídolo gótico. Ideología y creación de imágenes en el arte medieval, Akal: Madrid.

CARRERA SUÁREZ, Isabel (2000), “Feminismo y Poscolonialismo: estrategias de subversión” en FARIÑAS BUSTOS, Maria Jesús (ed.). Escribir en femenino, poéticas y políticas, Icaria: Barcelona, pp. 73-85.

FRANCASTEL, Pierre (1958), "Problèmes de la Sociologie de l'Art” en GURVITCH, Georges (1958). Traité de Sociologie, Presses Universitaires de France: Paris, vol. 2, pp. 402-429. FRANCASTEL, Pierre (Ed.) (1983). El impresionismo, Bruguera: Barcelona.

GOMBRICH, Ernst Hans Josef (1953), “The Social History of Art by Arnold Hauser”, The Art Bulletin, Vol. 35, No. 1 (Mar., 1953), pp. 79-84.

HATT, Michael, KLONK, Charlotte (2006). Art History: A Critical Introduction to its Methods, Manchester University Press: Manchester.

HAUSER, Arnold (Ed.) (1961). Introducción a la Historia del Arte, Guadarrama: Madrid.

HAUSER, Arnold (Ed.) (1993). Historia social de la literatura y el arte desde el Rococó hasta la época del cine, vol. 3, Labor: Barcelona.

HOOPER-GREENHILL, Elian (2000). Museums and the interpretation of Visual Culture, Routledge: London.

HUTCHEON, Linda (1989), "Circling the Downspout of Empire: Post-Colonialism and Postmodernism", Ariel ,vol. 20, nº. 4, Oct., pp. 149-175.

LACAN, Jacques (Ed.) (1964). El seminario de Jacques Lacan $n^{\circ} 11$ : los cuatro conceptos fundamentales del psicoanálisis, Paidós: Buenos Aires, Barcelona, Mexico.

LACAN, Jacques (Ed.) (2013). Escritos 1, Biblioteca Nueva: Madrid.

MARX, Karl (1982). Introducción general a la crítica de la economía política, Siglo XXI: México. MARÍAS, Fernando (1996). Teoría del Arte, vol. II, Historia 16, Información e Historia: Madrid. 